преподавателей. При этом отсутствие единых методологических подходов (точных критериев, единых требований, форм проведения) становится очевидным. Профессорскопреподавательский состав не владеет достаточными навыками по ведению занятий с использованием современных IT-технологий, что неизбежно требует повышения их «компьютерной грамотности». Кроме этого, появляются проблемы технического и технологического характера, усугубляются человеческий и психологический факторы.

$* * *$

1. Блоховцова Г.Г., Волохатых А.С. Перспективы развития дистанционного образования. Преимущества и недостатки // Символ науки. - 2016. - № 10 (2). - С. 119-121. [Электронный ресурс]. URL:"https://socionet.ru/publication.xml?h= spz:cyberleninka:32509:16914937" (дата обращения: 15.06.2021).

2. Государственная программа развития образования и науки Республики Казахстан на 2020 - 2025 годы. Постановление Правительства Республики Казахстан от 27 декабря 2019 года № 988. [Электронный ресурс]. URL:"https://adilet.zan.kz/rus/docs/P1900000988" (дата обращения: 16.06.2021).

3. Штыхно Д.А., Константинова Л.В., Гагиев Н.Н. Переход вузов в дистанционный режим в период пандемии: проблемы и возможные риски. Открытое образование. 2020;24(5):72-81. [Электронный ресурс]. URL:"https://doi.org/10.21686/1818-4243-2020-5-72-81" \t "_blank" (дата обращения: 15.06.2021).

4. Рогачёва П.С., Семергей С.В. Проблемы дистанционного образования в период пандемии // Вестник Майкопского государственного технологического университета. 2020. Том 12, № 4. С. 85-93. [Электронный pecypc]. URL:"https://doi.org/10.47370/2078-1024-2020-12-4-85-93" (дата обращения: 11.06.2021).

\title{
Соловьева Н.В. \\ Анализ предпочтений видов физической активности студентами ПетрГУ на занятиях по дисциплине «Физическая культура и спорт»
}

Петрозаводский Государственный университет (Россия, Петрозаводск)

doi: 10.18411/trnio-09-2021-61

\section{Аннотация}

В возникшей новой осложнённой эпидемиологической обстановке требуются новые подходы к организации учебного процесса по дисциплине «Физическая культура и спорт». В данной статье мы проводим анализ предпочтения видов и форм практических занятий по дисциплине со студентами института филологии 1, 2, 3 курсов Петрозаводского государственного университета за учебный семестр с целью оптимизации и улучшения качества работы в данном направлении.

Ключевые слова: физическая культура, дистанционное обучение, самостоятельная работа, учебная работа, студенты.

\section{Abstract}

In the new complicated epidemiological situation that has arisen, new approaches to the organization of the educational process in the discipline "Physical culture and sport" are required. In this article, we analyze the preferences of the types and forms of practical classes in the discipline with students of the Institute of Philology 1, 2, 3 courses of Petrozavodsk State University for the academic semester in order to optimize and improve the quality of work in this direction.

students.

Keywords: physical culture, distance learning, independent work, educational work,

В соответствии с ФГОС ВО, дисциплина «Физическая культура и спорт» (далее «ФК») реализуется только в форме практических занятий. Нынешние реалии в организации проведения групповых занятий в связи со сложной эпидемиологической обстановкой наложили свой отпечаток. С учетом требований ФГОС ВО кафедре физической культуры Петрозаводского государственного университета (ПетрГУ) пришлось перестаивать учебный процесс, добавляя частично дистанционный формат обучения [1]. Новая форма организации учебного процесса в этих непростых условиях включает разнообразные варианты заданий, 
которые в комплексе позволяют поддерживать должный уровень физического здоровья, добиться осознанного отношения к самостоятельным занятиям физической культурой на основе тщательного самоанализа. Данная работа ведётся в соответствии с общим разработанным «Положением об организации учебного процесса по дисциплине «Физическая культура и спорт», контролируется преподавателями кафедры.

В данной статье проведём анализ предпочтения видов и форм практических занятий по дисциплине «Физическая культура и спорт» студентами института филологии 1, 2, 3 курсов Петрозаводского государственного университета за учебный семестр в условиях осложнённой эпидемиологической ситуации.

Все формы и варианты двигательной активности в начале семестра прописаны в «Положении об организации учебного процесса» по дисциплине «Физическая культура и спорт». Промежуточная аттестация проводится в формате зачёта. При оценивании работы студентов используется балльная система. Балльная оценка по дисциплине - это сумма баллов, набранных студентом в результате работы в семестре. Она складывается из баллов, полученных при посещении очных занятий, баллов за дистанционную практическую работу, баллов, полученных за результаты тестирования, дополнительных и бонусных баллов.

В сложившейся ситуации к практическим занятиям, проводимым с уменьшенным числом студентов на открытых площадках и спортивных объектах, добавились тренировки с использованием системы видеосвязи ZOOM.

Дистанционные формы занятий, организованные в данный период: самостоятельная работа с использованием мобильного приложения Strava, самостоятельно выполненная тренировка с видео-отчётом, дополнительные занятия в спортивных клубах и спортивных, походы выходного дня [2].

Бонусные баллы начисляются за участие в спортивно-массовых и физкультурнооздоровительных мероприятиях, проводимые как в традиционном формате, так и в онлайн режимах, за участие в научно-исследовательской деятельности и научных конференциях.

В представленных ниже таблицах приведены варианты выбранных работ по дисциплине среди обучающихся 1, 2, 3 курсов и показатели выполнения. Анализируя результаты можно сделать вывод, что предпочтения, выраженные в процентном соотношении, почти одинаковы у студентов разных курсов и приоритет отдан дистанционной работе с использованием приложение Strava. Практическую работу, проводимую в очном формате, как и предполагалось, выбирают обучающиеся 1 курса, так как идёт процесс адаптации и обучения новым практическим навыкам, организации своей деятельности. А вот вариант самостоятельных домашних тренировок, требуемых видеоотчёта с большим преимуществом предпочли третьекурсники, которые уже готовы и могут реализовать себя в самостоятельной работе, готовы к самоорганизации и более уверены в своих практических навыках и знаниях.

\begin{tabular}{|c|c|c|c|c|c|c|}
\hline & страва & $\begin{array}{c}\text { видео } \\
\text { отчетьл }\end{array}$ & $\begin{array}{l}\text { онлайн } \\
\text { занятия }\end{array}$ & $\begin{array}{c}\text { занятия } \\
\text { очно }\end{array}$ & $\begin{array}{c}\text { дополнительные } \\
\text { балльь }\end{array}$ & noxodbl \\
\hline $\begin{array}{c}\text { Количество } \\
\text { обучаюшихся } 3 \\
\text { курса }\end{array}$ & 550 & 424 & 66 & 140 & 94 & 86 \\
\hline проченты & 40,44 & 31,17 & 4,85 & 10,29 & 6,9 & 6,3 \\
\hline
\end{tabular}

\begin{tabular}{|c|c|c|c|c|c|c|}
\hline & страва & $\begin{array}{c}\text { видео } \\
\text { отчеть }\end{array}$ & $\begin{array}{l}\text { онлайн } \\
\text { занятия }\end{array}$ & $\begin{array}{c}\text { занятия } \\
\text { очно }\end{array}$ & $\begin{array}{c}\text { дополнительные } \\
\text { балльь }\end{array}$ & noxodbl \\
\hline $\begin{array}{c}\text { Количество } \\
\text { обучаюшихся } 2 \\
\text { курса } \\
\end{array}$ & 985 & 173 & 202 & 350 & 212 & 96 \\
\hline проченты & 48,81 & 8,6 & 10 & 17,3 & 10,5 & 4,7 \\
\hline
\end{tabular}


Таблица 2

\begin{tabular}{|c|c|c|c|c|c|c|}
\hline & страва & $\begin{array}{c}\text { видео } \\
\text { отчеты }\end{array}$ & $\begin{array}{c}\text { онлайн } \\
\text { занятия }\end{array}$ & $\begin{array}{c}\text { занятия } \\
\text { очно }\end{array}$ & $\begin{array}{c}\text { дополнительные } \\
\text { балльь }\end{array}$ & походы \\
\hline $\begin{array}{c}\text { Количество } \\
\text { обучающихся 1 } \\
\text { курса }\end{array}$ & 1418 & 62 & 235 & 671 & 183 & 152 \\
\hline в прочентах & 51,1 & 2,27 & 8,6 & 24,7 & 6,7 & 5,6 \\
\hline
\end{tabular}

Чтобы узнать мнение студентов ПетрГУ о дистанционном формате занятий по «ФК» было опрошено некоторое количество обучающихся, которым было задано 5 вопросов:

«Нравится ли вам дистанционньй формат занятий по ФК?», «Что нравится больше всего? (онлайн занятия с использованием ZОOМ/прогулки с использованием приложения Strava? запись видео тренировок)», "Что нравится меньше всего? Почему?», "Довольны ли Bы существующей системой оценивания дистанционных занятий? Да/Нет. Если нет, почему?», «Есть ли какие-либо предложения о том, как можно улучшить проведение дистанционных занятий по ФК?».

Абсолютное большинство высказало мнение, что им нравится формат дистанционных занятий, принятый в нашем университете. По поводу любимого формата занятий мнения разделились. Примерно 43\% опрошенных назвали своим любимым форматом «прогулки с использованием приложения Strava». Следующими по популярности стали занятия с использованием платформы ZOOM (примерно 36\% опрошенных), оставшийся 21\% назвал своим любимым видом дистанционных занятий по «ФК» самостоятельные тренировки с последующим видео-отчетом.

Фаворитом же среди самых нелюбимых форматов стала самостоятельная видео тренировка. Многие отмечают, что такой формат кажется им некомфортным. Одним потому, что они чувствуют неловкость, снимая себя на камеру, у других нет возможности заниматься дома из-за недостатка места или какого-либо спортивного снаряжения, кто-то не может снять видео по техническим причинам. Малая часть опрошенных отметила, что им не нравятся прогулки с использованием приложения Strava по причине его периодической некорректной работы и несоответствия затраченных усилий количеству получаемых баллов.

По этой же причине большая часть опрошенных ответила на четвёртый вопрос "Довольны ли Bbl существующей системой оценивания дистанционных занятий» отрицательно. Во многом такое отношение к системе оценивание связано с тем, что количество требуемых для получения баллов осталось примерно таким же, как и до пандемии и начала дистанционных занятий, но теперь требуется больше времени и сил, чтобы заработать нужное количество.

Подводя итоги стоит сказать, что большинству студентов нравится дистанционный формат занятий. В особенности это касается самостоятельных форм работы (прогулок с использованием приложения Strava и видео тренировок), так как они позволяют обучающимся самим выбирать удобное время для тренировок, место и формат.

Делая выводы, можно сказать, что дистанционный формат проведения занятий по дисциплине «Физическая культура и спорт», реализованный в ПетрГУ, это неизбежный компромисс между необходимостью поддерживать физическое здоровье студентов, их безопасностью и комфортом. Как и всё, появившееся в столь сложных обстоятельствах, этот формат имеет свои недостатки, проблемы и сложности. Но единственный путь их устранения лежит в диалоге студентов и преподавателей. Сейчас недавно появившаяся система дистанционных занятий работает хорошо, но всё ещё не стабильно. Исправить это возможно только в процессе совместной работы.

$$
* * *
$$

1. Соловьева Н.В. Опыт кафедры физической культуры ПетрГУ в решении задач дистанционного обучения со студентами гуманитарных направлений подготовки [Электронный ресурс] / Н.В. Соловьева, В.Н. Кремнева // Тенденции развития науки и образования. - НИЦ «Л-Журнал», 2020. - Вып.61, №61/13. - С.7-10.

2. Кремнева В.Н. Анализ эффективности системы дистанционного обучения в предметной области «Физическая культура» [Текст] / В.Н. Кремнева, А.С. Кариаули // ученые записки университета им. П.Ф. Лесгафта. - Москва, 2020. - №6 (184). - С.34-37. 